\title{
Based on the traffic system tools magneto electric equipment design and application
}

\author{
Jian Sun, Lu Lyu, Yan Yang, Yan-ling Bai, Wen-li Jin, Yong Ren, and Lin-lin Zhang \\ Equipment manufacturing center, Institute of China Electronics technology group co., LTD. 28, Nanjng, China
}

\begin{abstract}
In transportation, the road is rough, the engine operation, the instability of the transmission system, and large vibration of the vibration system is to collect the vibration energy, and transformed into stable electricity, provide extra energy for transportation. Experiment device of the system is composed of three parts: simulate vibration test rig, vibration generating device, rectifier voltage regulator circuit. Vibration table is to simulate vehicle vibration in the road, cars, for example, through the check information that cars drive in ordinary road driving axle of some vibration data, thus to calculate all parameters of the vibration table. Vibration generating device is placed on the simulation vibration table, it can convert vibration energy into cars can use electricity. Rectifier voltage regulator circuit is generated by power generation device with a range of random variation of amplitude of electric energy through the rectifier voltage into a stable power output, for car use. The final design and making the vibration system, obtained by the method of experiment proved that the vibration of system feasible.
\end{abstract}

\section{The background and significance}

Vibration is ubiquitous in the transportation, it not only consume much energy, and bring the noise and vibration, reducing the comfort and stability. But the vibration is hard to avoid in the transportation, usually in order to reduce the loss of the vibration and the vibration will install some shock absorption on the mechanical design. In this paper, we study and design on the vibration of the vehicles produced in the process of driving the recovery and utilization system, through this system, the vibration in the vehicle running hard to eliminate forms of energy conversion, reasonably be can use energy. Compared with ordinary suspension mechanism, vibration system can be used to collect and convert vibration energy and can improve the efficiency of energy utilization if efficient use of the energy.

Because our country most of the pavement is class B (cement and asphalt) or $\mathrm{C}$ level road, therefore assume that car is in grade B road on GB7031 according to the road pavement power spectral density according to the rough degree is divided into 8 , also stipulates that the scope of all levels of road roughness coefficient and the geometric average, the frequency of the grading road roughness index to 2 , shown in the following table. Cars in the driving process, and different speed, different grades of road surface pavement roughness incentives are different. Road surface model is road roughness on the road grade and the mathematical description of the car speed variation. Table 2 as a vehicle for a domestic car technical parameters, using the simulation toolkit (Simulink), can be obtained under the system parameters and the road excitation Angle of sprung mass and the output of the sprung mass center displacement curve. Combining general speed is within the scope of the 36 $108 \mathrm{~km} / \mathrm{h}$, the corresponding wheel input time between $0.1 \sim 75 \mathrm{hz}$ frequency range, the inherent frequency of the suspension system in $1 \sim 2 \mathrm{hz}$, part of the suspension system inherent frequency in $10 \sim 16 \mathrm{hz}$. Shock absorber in the $10 \sim 16 \mathrm{hz}$ frequency range when it sprung mass center displacement amplitude on - $40 \mathrm{db}$. After the suspension system is calculated the frame vibration amplitude is about $2 \mathrm{~cm}$. So magnetoelectric vibration generator design work environment is: the automobile speed in the $36-108 \mathrm{~km} / \mathrm{h}$, on B road, vibration generated by the road and vehicle itself incentive the rear axle, produced by the vibration frequency range for 10 to $16 \mathrm{hz}$, vibration amplitude around $2 \mathrm{~cm}$.

Table 1. The power spectral density coefficient of road surface roughness and the response of the body

\begin{tabular}{|c|c|c|c|c|c|c|c|c|c|c|c|c|}
\hline \multirow{3}{*}{$\begin{array}{l}\text { road } \\
\text { level }\end{array}$} & \multirow{2}{*}{\multicolumn{3}{|c|}{$\begin{array}{l}G_{0}\left(\eta_{0}\right) \times 10^{-6} m^{-2} \\
n_{0}=0.1 m^{-1}\end{array}$}} & \multicolumn{9}{|c|}{$a_{w} /\left(\mathrm{m} \cdot s^{-2}\right)$} \\
\hline & & & & \multicolumn{3}{|c|}{$\mathrm{V}=80 \mathrm{~km} / \mathrm{h}$} & \multicolumn{3}{|c|}{$\mathrm{V}=100 \mathrm{~km} / \mathrm{h}$} & \multicolumn{3}{|c|}{$\mathrm{V}=120 \mathrm{~km} / \mathrm{h}$} \\
\hline & 1 & 2 & 3 & 1 & 2 & 3 & 1 & 2 & 3 & 1 & 2 & 3 \\
\hline$A$ & 8 & $\begin{array}{l}1 \\
6\end{array}$ & $\begin{array}{l}3 \\
2\end{array}$ & $\begin{array}{l}0 . \\
18 \\
3\end{array}$ & $\begin{array}{l}0 . \\
25 \\
6\end{array}$ & $\begin{array}{l}0 . \\
36 \\
6\end{array}$ & $\begin{array}{l}0 . \\
20 \\
3\end{array}$ & $\begin{array}{l}0 . \\
28 \\
7\end{array}$ & $\begin{array}{l}0 . \\
40 \\
6\end{array}$ & $\begin{array}{l}0 . \\
21 \\
8\end{array}$ & $\begin{array}{l}0 . \\
30 \\
9\end{array}$ & $\begin{array}{l}0 . \\
43 \\
6\end{array}$ \\
\hline$B$ & $\begin{array}{l}3 \\
2\end{array}$ & $\begin{array}{l}6 \\
4\end{array}$ & $\begin{array}{l}1 \\
2 \\
8\end{array}$ & $\begin{array}{l}0 . \\
36 \\
6\end{array}$ & $\begin{array}{l}0 . \\
51 \\
8\end{array}$ & $\begin{array}{l}0 . \\
73 \\
2\end{array}$ & $\begin{array}{l}0 . \\
40 \\
6\end{array}$ & $\begin{array}{l}0 . \\
57 \\
4\end{array}$ & $\begin{array}{l}0 . \\
81 \\
2\end{array}$ & $\begin{array}{l}0 . \\
43 \\
6\end{array}$ & $\begin{array}{l}0 . \\
61 \\
7\end{array}$ & $\begin{array}{l}0 . \\
87 \\
3\end{array}$ \\
\hline $\mathrm{C}$ & $\begin{array}{l}1 \\
2 \\
8\end{array}$ & $\begin{array}{l}2 \\
5 \\
6\end{array}$ & $\begin{array}{l}5 \\
1 \\
2\end{array}$ & $\begin{array}{l}0 . \\
73 \\
2\end{array}$ & $\begin{array}{l}1 . \\
03 \\
5\end{array}$ & $\begin{array}{l}1 . \\
46 \\
4\end{array}$ & $\begin{array}{l}0 . \\
81 \\
2\end{array}$ & $\begin{array}{l}1 . \\
14 \\
8\end{array}$ & $\begin{array}{l}1 . \\
62 \\
3\end{array}$ & $\begin{array}{l}0 . \\
87 \\
3\end{array}$ & $\begin{array}{l}1 . \\
23 \\
4\end{array}$ & $\begin{array}{l}1 . \\
74 \\
4\end{array}$ \\
\hline
\end{tabular}


Table 2. A domestic car vehicle technical parameters

\begin{tabular}{|c|c|c|c|}
\hline parameter & $\begin{array}{c}\text { The } \\
\text { numerical }\end{array}$ & parameter & $\begin{array}{c}\text { The } \\
\text { numerical }\end{array}$ \\
\hline $\mathrm{M}(\mathrm{kg})$ & 975.37 & $C_{1}(N \cdot \mathrm{s} / \mathrm{m})$ & 2546.5 \\
\hline$m_{1}(\mathrm{~kg})$ & 98 & $C_{1}(N \cdot \mathrm{s} / \mathrm{m})$ & 2480.6 \\
\hline$m_{2}(\mathrm{~kg})$ & 98 & $K_{\mathrm{t} 1}(N / \mathrm{m})$ & 604684.5 \\
\hline$K_{1}(N / m)$ & 45482.2 & $K_{\mathrm{t} 2}(N / m)$ & 985865 \\
\hline$K_{1}(N / m$ & 52288.2 & $\mathrm{a}(\mathrm{m})$ & 1.1135 \\
\hline $\mathrm{b}(\mathrm{m})$ & 1.5415 & $\mathrm{~J}\left(\mathrm{Kg} \cdot \mathrm{m}^{2}\right)$ & 863.2 \\
\hline
\end{tabular}

\section{The design of the system vibration}

Vehicle vibration system is shown in figure 1, includes the following parts: electromagnetic vibration generating device, rectifier voltage regulator circuit, simulation vibration table.

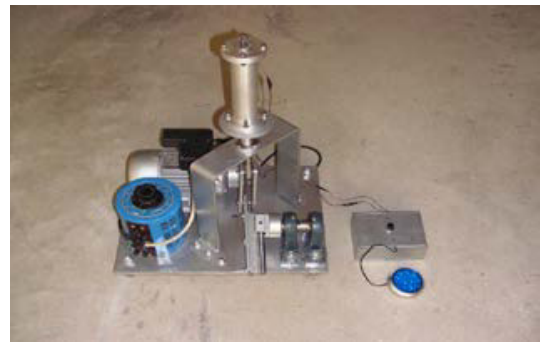

Figure 1. Vibration system.

\section{Electromagnetic vibration generating device}

Cars on the vibration of each part has its different directions, with similar principle to design the magnetoelectric sensor vibration collection and conversion of power generation equipment, through the different parts of the car, different directions, to install the device, to a certain direction vibration is converted into mechanical energy through the power of the device can use of electricity. Electromagnetic vibration generating device with the method of permanent magnet in place, it is composed of permanent magnet, spindle, coils, springs, linear bearing and the shell, etc. Permanent magnet is installed on the spindle, spindle on both ends of the spring end respectively fixed on the end cover shell, the other end, respectively, to resist the spindle, it plays the role balance reset, coil is fixed on the outside of the permanent magnet. Work in the process of permanent magnet reciprocating motion in the coil, an electrical current to cutting magnetic induction line. Because the car axle is directly from under such as uneven ground, engine running, the vibration incentives, such as transmission system is not smooth, so in the actual application can install multiple vibration generating device to the car's axle parts, so that it can be larger to collect vehicle vibration energy and convert it into electrical energy can be used. Vibration generating device of the three-dimensional figure as shown in figure 2, figure 3 for the real figure.

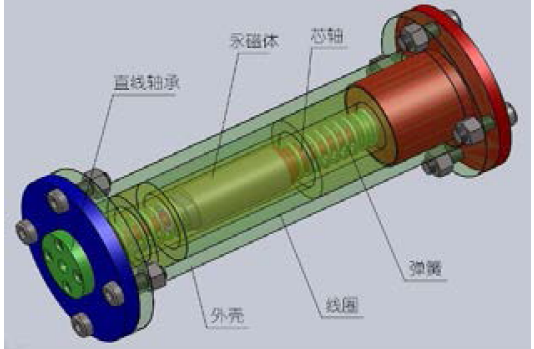

Figure 2. Vibration generator for three dimensional figure.

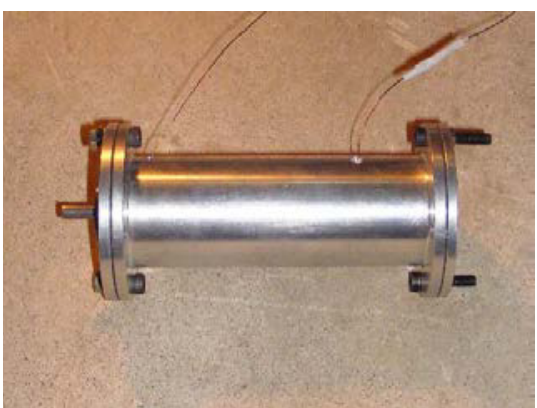

Figure 3. Vibration generator for real figure.

\section{Voltage regulator rectifier device}

Due to the different parts of the vibration amplitude is different, the resulting current size are different, the car can use voltage have special requirements, it is necessary to design a voltage regulator rectifier device, a voltage to integration of the magneto electric generator for producing, in order to meet specific application requirements. According to the design requirements of electromagnetic vibration generating device, you need to generator output alternating current (amplitude of $16 \mathrm{v}$ ) could satisfy the requirement of storage battery is converted into direct current $(12 \mathrm{v})$. Thus we design a simple dc voltage system. Figure 4 is to convert alternating current (ac) to conform to the conditions of direct current $(\mathrm{dc})$ diagram.

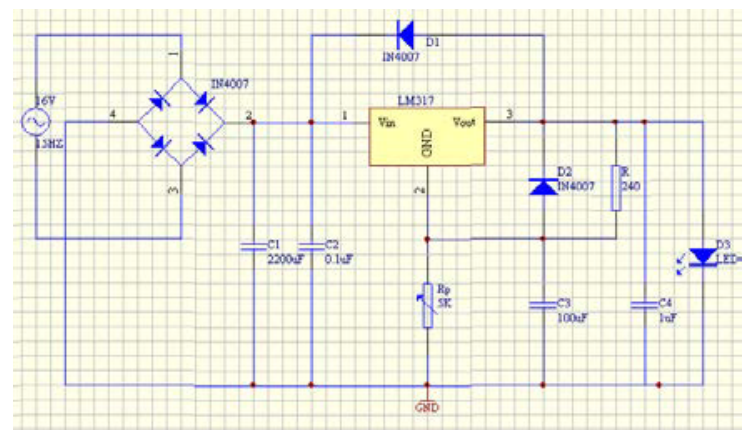

Figure 4. Circuit diagram.

\section{5 simulation vibration table}

Design the device in the product development phase, the purpose is approximately simulated vibration in the process of driving vehicle situation, it would not have to for real vehicle experiment, with the real vehicle experiment is very complex, and it is time consuming, high cost, bad for the project. As the automobile rear axle initial pavement displacement, encouragement is affected 
by the surface roughness, and uneven road surface is a random process, with irregularity and self-similarity, showed obvious fractal characters, so the surface roughness have the fractal characteristics of chaos, so the simulation vibration table using chaotic vibration principle, the connecting rod slide block mechanism, the number of freedom degree is greater than the original dynamic mechanism of, by the mechanical principles known even move a deterministic input, output can still irregular vibration. Structure principle as shown in figure 5, Figure zhongyuan moving crank for uniform rotation driven by a motor. Uniform rotation, although a crank and connecting rod slider mechanism for no clearance, but the freedom degree is greater than the original number, Freedom degree of the $\underset{\text { organization }}{F}=3 n-2 P_{L}-2 P_{h}=3$, The number of components is $n$, Low number of vice is $P_{L}$, High number of vice is $P_{h}$. So, the design of the connecting rod slider vibrator, should be able to make the movement of the workbench has chaotic characteristics, to better simulate complex vibration when the car driving on the road.

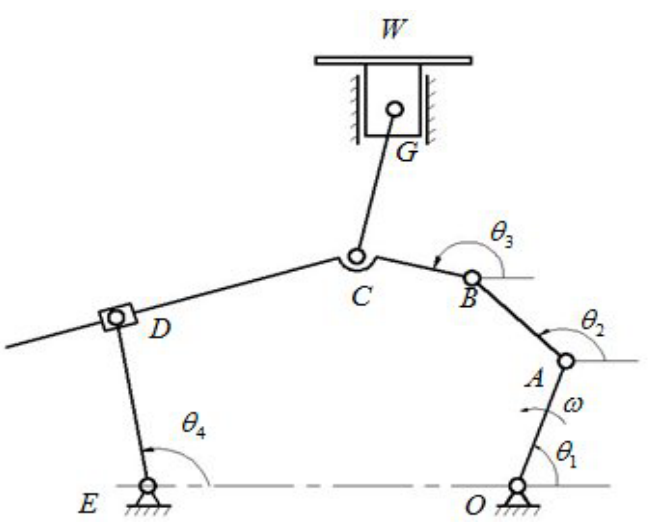

Figure 5. Vibration platform agencies diagram.

$$
\begin{aligned}
& \text { Frequency: } f=10 \sim 16 \mathrm{~Hz} \\
& \text { The amplitude: } \mathrm{A}=0 \sim 20 \mathrm{~mm}
\end{aligned}
$$

Under the above conditions by the calculation and simulation with given size parameters of the mechanism motion: $\mathrm{OA}=18 \mathrm{~mm}, \mathrm{AB}=3 \mathrm{~mm}, \mathrm{BC}=111.5 \mathrm{~mm}, \mathrm{DE}=3 \mathrm{~mm}$, $\mathrm{EO}=167 \mathrm{~mm}, \mathrm{DC}=180 \mathrm{~mm}, \mathrm{CG}=100 \mathrm{~mm}$.

Using Pro/E software to simulate the vibration test-bed for $3 \mathrm{~d}$ modeling, obtained by mechanism motion simulation vibration table of displacement, velocity and acceleration curve. As shown in figure 6-7.

By the simulation of displacement, velocity and acceleration curve, the average amplitude of vibration platform is $14.5 \mathrm{~mm}$, the maximum amplitude of vibration platform is $20 \mathrm{~mm}$, the minimum amplitude of vibration platform is $0.7 \mathrm{~mm}$, the maximum speed of vibration platform is $771 \mathrm{~mm} / \mathrm{s}$, the maximum acceleration of vibration platform is $330709 \mathrm{~mm} / \mathrm{s}^{2}$.

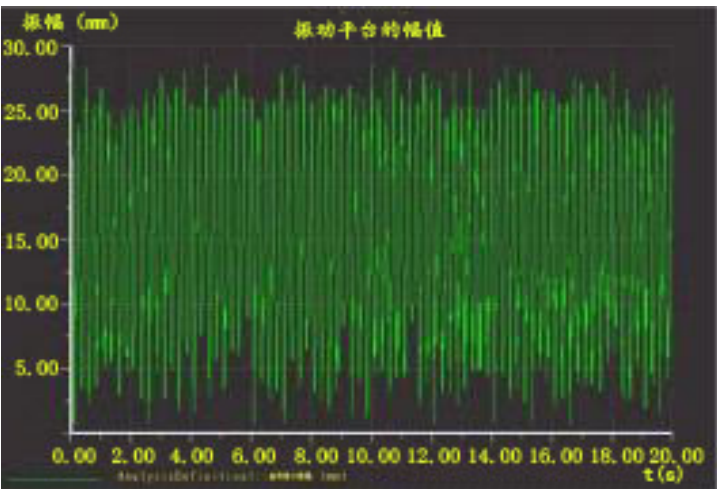

Figure 6. The amplitude of vibration platform.

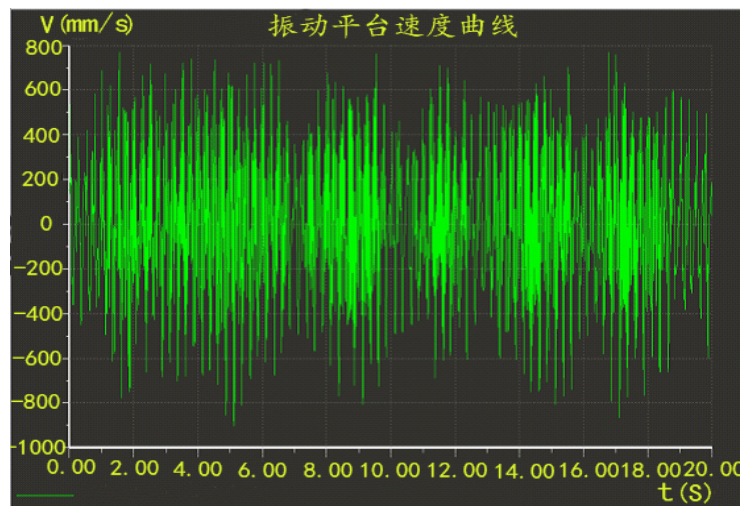

Figure 7. Vibration platform speed curve.

\section{The experiment and analysis}

Due to the different parts of the vibration amplitude is different, the resulting current size are different, the car can use voltage have special requirements, it is necessary to design a voltage regulator rectifier device, a voltage to integration of the magnetoelectric generator for producing, in order to meet specific application requirements. According to the design requirements of electromagnetic vibration generating device, you need to generator output alternating current (amplitude of $16 \mathrm{v}$ ) could satisfy the requirement of storage battery is converted into direct current (12 v). Thus we design a simple dc voltage system.

The determination of rectifier voltage part parameters: Rectification: the bridge type single-phase rectifier circuit. Known input maximum voltage $=16 \mathrm{v}$, maximum current input.IN4007 acuity $50 \mathrm{v}$ st13, reverse breakdown voltage of the rated working current $=800 \mathrm{ma}$, reason of selecting IN4007 diode rectifier bridge. Filtering: because small output current in the circuit, capacitor filter circuit can be used. Capacitor filter on engineering application in general have formula or greater $(3 \sim 5) / 2$. We make $=5$ $\mathrm{x} / 2=2.5 \mathrm{x}=2.5 /+=2.5 /(\mathrm{x})=2.5 /(\mathrm{x})=2083 \mathrm{uF}$, voltage $=1.2=13.6$ V.So choose $=2200$ uf, $50 \mathrm{v}$ electrolytic capacitor. For load resistance, capacitor for ac voltage cycles, as ac voltage and frequency as the input voltage, input current. Voltage regulation: the adjustable voltage regulator integrated three-terminal voltage regulator LM317.LM317 output voltage can be adjusted through the potentiometer, approximation is expressed as: $=1.25 \times(1+/) .=12 \mathrm{v}$ dc output voltage according to request, take $=240 \Omega$, computing available $=2064 \Omega$, take value for a $5 \mathrm{k} \Omega$ slide rheostat can meet. Is produced 
to prevent self-excited oscillation, its values range between $0.1 \sim 1 \mathrm{u} \mathrm{F}$, take in the design of the $0.1 \mathrm{u} \mathrm{F}$; And, protection, which typically take $100 \mathrm{u} \mathrm{F}$; Through the simple dc voltage system, we can get that could satisfy the requirement of automobile storage battery dc $12 \mathrm{v}$ voltage, in order to realize to the battery charging process. In addition we will install a reserve battery, when the car battery charged to reserve battery recharged, make full use of so as to realize the electrical energy. For the diode).Through the simple dc voltage system, we can get that could satisfy the requirement of automobile storage battery dc $12 \mathrm{v}$ voltage, in order to realize to the battery charging process. In addition we will install a reserve battery, when the car battery charged to reserve battery recharged, make full use of so as to realize the electrical energy.

\section{Frequency domain characteristics analysis of generator}

By the structure of the magnetoelectric vibration generator, the permanent magnet on receipt of the external random vibration frequency response can be used when the quality - spring - damper model, model diagram as shown in Figure 8.

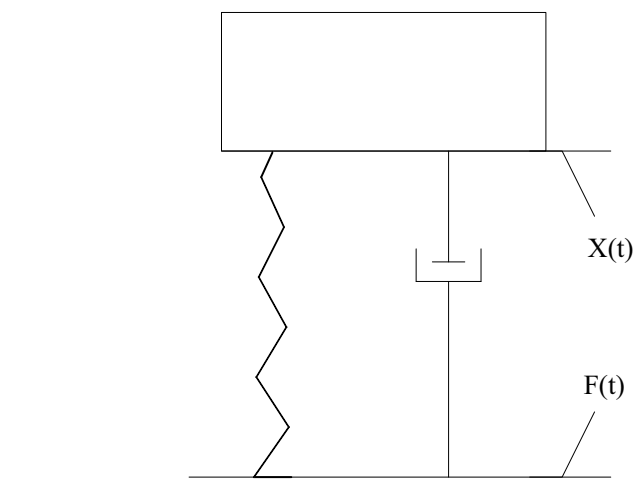

Figure 8. Quality - spring - damper model.

By Newton's laws of motion can be obtained under arbitrary excitation system of forced vibration differential equation for:

$$
f(t)=m \frac{d^{2} x(t)}{d t^{2}}+c \frac{d x(t)}{d t}+k x(t)
$$

Type of axial displacement function for permanent magnets, sum of permanent magnet and the quality of the spindle, for the system damping coefficient, the elastic coefficient of spring. In the initial conditions to zero, to pull its transformation, the transfer function of system is:

$$
G_{1}(s)=\frac{X(s)}{F(s)}=\frac{1}{m s^{2}+c s+k}
$$

And by the principle of voltage available:

$$
L \frac{d I(t)}{d t}+\left(R+R_{c}\right) I(t)=B l \frac{d x(t)}{d t}
$$

Type of coil inductance, as induced current changing with the time function, load resistance to vibration generator is connected, for the coil resistance, as the remanence intensity, the length of the coil. To pull transformation type (3):

$$
G_{2}(s)=\frac{I(s)}{X(s)}=\frac{B l s}{L s+R+R_{c}}
$$

Because the voltage $V=I(t) R$, so permanent magnet displacement and the output voltage of the transfer function for:

$$
\frac{V(s)}{X(s)}=\frac{B l R s}{L s+R+R_{c}}
$$

Due to the induced current in coil will give a negative feedback system, for its transfer function

$$
G_{3}(s)=\frac{B l}{R}
$$

By type (2) and (4) (6) the system must transfer function is:

$$
G(s)=\frac{V(s)}{F(s)}=\frac{G_{1}(s) G_{2}(s)}{1+G_{1}(s) G_{2}(s) G_{3}(s)}
$$

Due to the small and can be ignored, after finishing the system overall transfer function is:

$$
G(s)=\frac{V(s)}{F(s)}=\frac{B l R s}{\left[R\left(m s^{2}+c s+k\right)+(B l)^{2} s\right]}
$$

According to the calculation formula of permanent magnet in the permanent magnet motor:

$$
V_{\mathrm{m}}=51 \frac{P_{N} \sigma_{0} K_{a d} K_{\mathrm{dF}}}{f K_{\vartheta} K_{\mathrm{u}} C(B M)_{\max }} * 10^{9} \mathrm{~mm}^{3}
$$

Automotive vibration is inevitable in the process of driving, and makes a considerable part of the energy loss, also has brought the noise and vibration at the same time, lower the car's comfort and stability. These can cause the vibration of the car, and are hard to use technical means to eliminate the vibration for the car run has brought many unfavorable factors such as inadequate performance play, economy becomes bad, through natural bad handling stability, peace, damaged parts, shorten service life and so on. So imagine a car that can collect the vibration of generating unit, the vibration of mechanical energy into electricity, as part of the car electrical system provides additional power, so as to achieve the aim of improve the efficiency of the automotive fuel use. 


\section{Conclusion}

Automotive vibration is inevitable in the process of driving, and makes a considerable part of the energy loss, also has brought the noise and vibration at the same time, lower the car's comfort and stability. With the popularity of cars, the vibration energy losses have reached a certain proportion, in global energy increasingly scarce, and China is mainly under the background of construction of economical society, make full use of energy to become a problem we must solve. The vibration of the vehicle from several aspects such as the road is rough, the change of the speed and direction, wheels, the engine and transmission system is not smooth, the impact of the gear, etc. These can cause the vibration of the car, and are hard to use technical means to eliminate the vibration for the car run has brought many unfavorable factors such as inadequate performance play, economy becomes bad, through natural bad handling stability, peace, damaged parts, shorten service life and so on. So imagine a car that can collect the vibration of generating unit, the vibration of mechanical energy into electricity, as part of the car electrical system provides additional power, so as to achieve the aim of improve the efficiency of the automotive fuel use.

Vibration generating device could be common in the transportation of vibrations into usable energy, Using the built-in permanent magnet generating set to a larger extent realize energy conversion, also has a shaking table and adjustable rectifier voltage regulator circuits. Not only that it has a simple structure easy manufacturing, polluting the environment, changing volume, sustainable power and high efficiency etc., can be applied to a variety of mechanical vibration, the application prospect is broad.

\section{References}

1. TANG Koulin. Analysis of weather environment impact on electromagnetic situation [J]. Command Information System and Technology,2014,5(5) :20-24.(in Chinese)

2. CHEN ping. Global air traffic management(ATM)operational concept and its enlightenment $[\mathrm{J}]$. The command information system and technology, 2015, 6(4) : 1-6. (in Chinese)
3. The command information system and technology, 2012, 3 (1) : 25 to 28

4. Cui Peng. The mechanism of debris flow initiation[Ph.D. Thesis][D]. Beijing: Beijing Forerstry University, 1990.(inChinese)

5. Cui P. Studies on condition and mechanism of debris flow initiationby means of experiment [J]. Chinese Science Bulletin, 1992, 37(9), 759-763.

6. Mark E R, Richard G L H, Richard M I. Debris-flow initiationexperiments using diverse hydrologic triggers[A]. In : Chen C L ed.Debris-flow Hazards Mitigation Mechanics, Prediction, andAssessment[C]. New York : [s. n. ], 1997. 1-11.

7. The command information system and technology, 2011, 02 (6) : 39-41

8. J. Bisplinghoff, J. Cormier, and S. Duma, Development and validation of eye injury and facial fracture criteria for the focus headform, Paper presented at the 26th Army Science Conference, Orlando, FL, 1-4 December, 2008.

9. C.K. Thorbole and H.M. Lankarani, Performance evaluation of computational HIC component tester for aerospace application, Paper No. 2008-01-2229, SAE International, Warrendale, PA, August 2008.

10. Chandler, R.F., "Human Injury Criteria Relative to Civil Aircraft Seat and Restraint System," SAE Paper 851847, society of Automotive Engineers, Warrendale,PA, 1985

11. The command information system and technology, 2011, 02 (6) : 39-41

12. Lissner, H.R., Lebow, M., and Evans, F.G., "Experimental Studies on the Relation between Acceleration and Intracranial Pressure Changes in Man," Surgery, Gynecology, and Obstetrics, V. 111, 1960, pp 329-338.

13. Yin Zhen. Electrodynamics (third edition). Beijing: science press, 2010.2.

14. Sun Guangfei, strong Wen Jiang. Magnetic functional materials. Beijing: chemical industry press, 2007.2.

15. into the big, mechanical design manual (fifth edition). Chemical industry press. 2007.

16. Zhao Jihai road roughness measurement, analysis and application of Beijing university of science and technology press. 